\title{
NUMERICAL MODELING OF MORPHODYNAMIC CHANGES IN THE JADE ESTUARY - GERMANY
}

\author{
Almut Gelfort ${ }^{1}$, Florian Ladage ${ }^{2}$ and Oliver Stoschek ${ }^{2}$
}

\begin{abstract}
Based on a case study sediment transport was modeled numerically for the Jade estuary. Due to the construction of the JadeWeserPort the morphology in the area is undergoing a relocation. The study gives an overview on various studies undertaken as a consultant tool to help designers and decisions makers. A hydrodynamic as well as a morphodynamic numerical model was set up. Although the input data on the morphodynamic part was limited, the results showed that the tool at hand is capable of producing reliable results in the field of modeling sediment transport.
\end{abstract}

Keywords: sediment transport, numerical modeling, morphodynamic, hydrodynamic, case study, Jade estuary, Jade Weser Port, MIKE 3 by DHI

\section{INTRODUCTION}

The world wide increase of cargo ship transportation during the past years led to an increased demand of new harbors as well as storage and trans-shipment areas for the large amount of containers. Instead of gaining these areas from land sites, these areas are often placed into a river or estuary, where the area itself is created by using landfill techniques. The material required for the landfill can be dredged in nearby areas, i.e. as part of the required dredging within the creation process of fairways. Afterwards this material is missing in the environment. This leads to a change in the morphology as well as the need to re-establish a balance of sediments in the affected areas. Furthermore, the replenished areas influence the currents, where the direction and the current velocities adjust to the new situation. Changing currents affect the morphodynamic situation as well.

In the area around a port constructed by landfill various investigations where undertaken to analyze the impact of the changing current situation and the dredged landfill material on designed constructions nearby. Therefore, numerical modeling of sediment transport was conducted and the morphological development was assessed from these models. A 3-dimensional numerical model was set up to investigate the sediment transport in the area of interest in terms of erosion and sedimentation processes. A number of scenarios were analyzed. Among others these scenarios include the investigation of morphodynamic changes in the area of interest during the construction period of the landfill area. Furthermore, the time frame for the natural re-deposition in the area of investigation was estimated as well as a final morphological state in the vicinity of the new port was determined.

\section{AREA OF INVESTIGATION}

The Jade estuary is located at the German North Sea coast. The estuary features more a bay, as the discharge of the Jade River can be neglected due to the very small amount of water (Fig. 1). The Jade estuary is influenced by the tides; the average tidal range at gauge Wilhelmshaven Old Port measured between 1989 and 1998 is $3.80 \mathrm{~m}$ (LANU, 2000).

The Jade estuary is one of the 5 major German estuaries discharging into the North Sea. In the river mouth or in the rivers of Ems, Weser and Elbe large ports exist. In the Northern part of the estuary (apart from the Wadden area) large water depth predominate the Jade estuary. Here a new deep water port (JadeWeserPort) is designed near the city of Wilhelmshaven.

\footnotetext{
${ }_{1}^{1}$ Hydrodynamic and Coastal Engineering Department, DHI-WASY GmbH, Max-Planck-Str. 6, 28857 Syke, Germany

${ }^{2}$ DHI-WASY GmbH, Max-Planck-Str. 6, 28857 Syke, Germany
} 


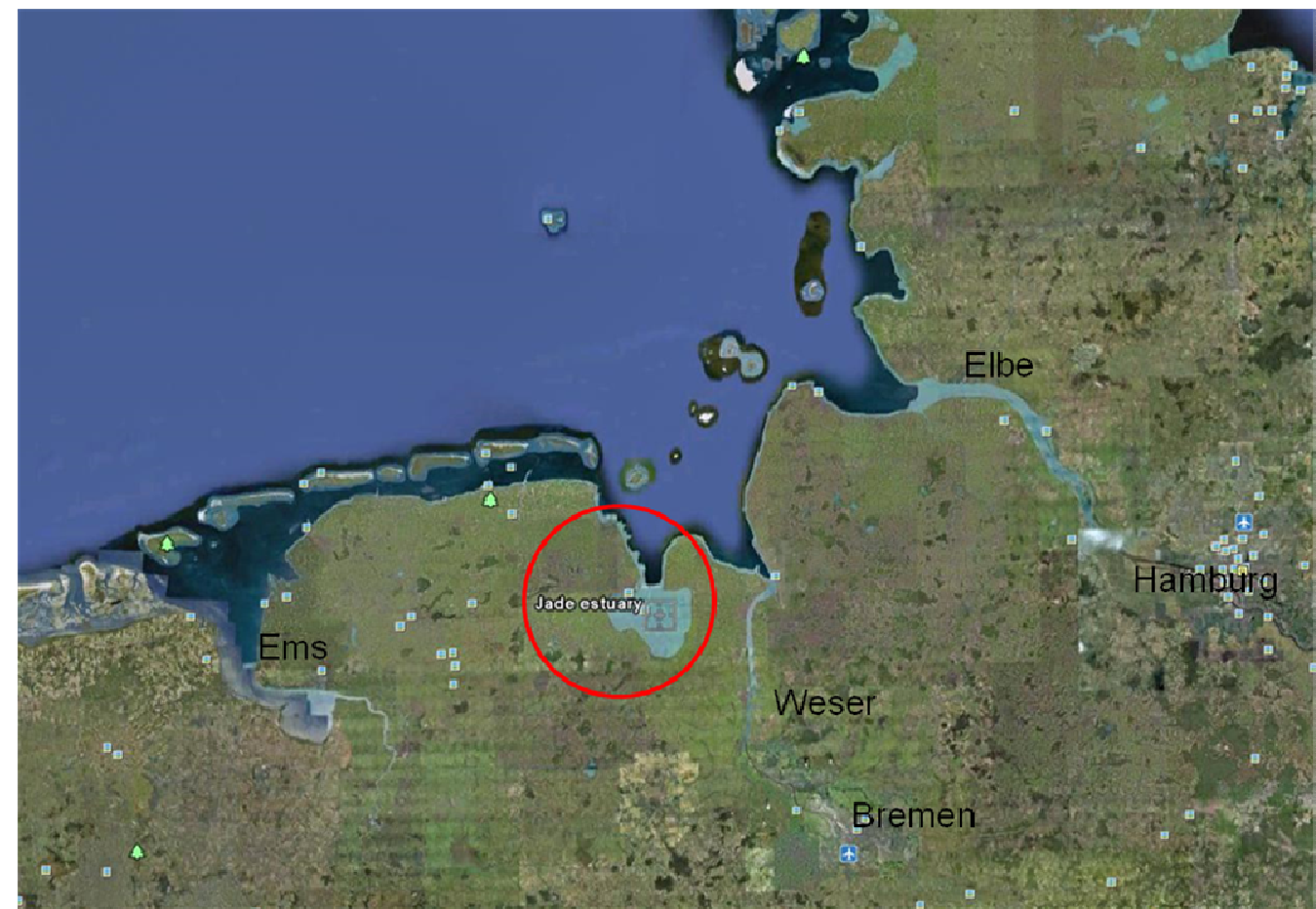

Figure 1. Satellite view of the German North Sea coast indicating the Jade Estuary [Source: Google Earth].

The area of the port is about 360 ha and of a quadrangular shape, where the pier runs along the eastern side and is about $1725 \mathrm{~m}$ long. The material for the landfill was taken from two nearby sites, as indicated in Fig. 2.

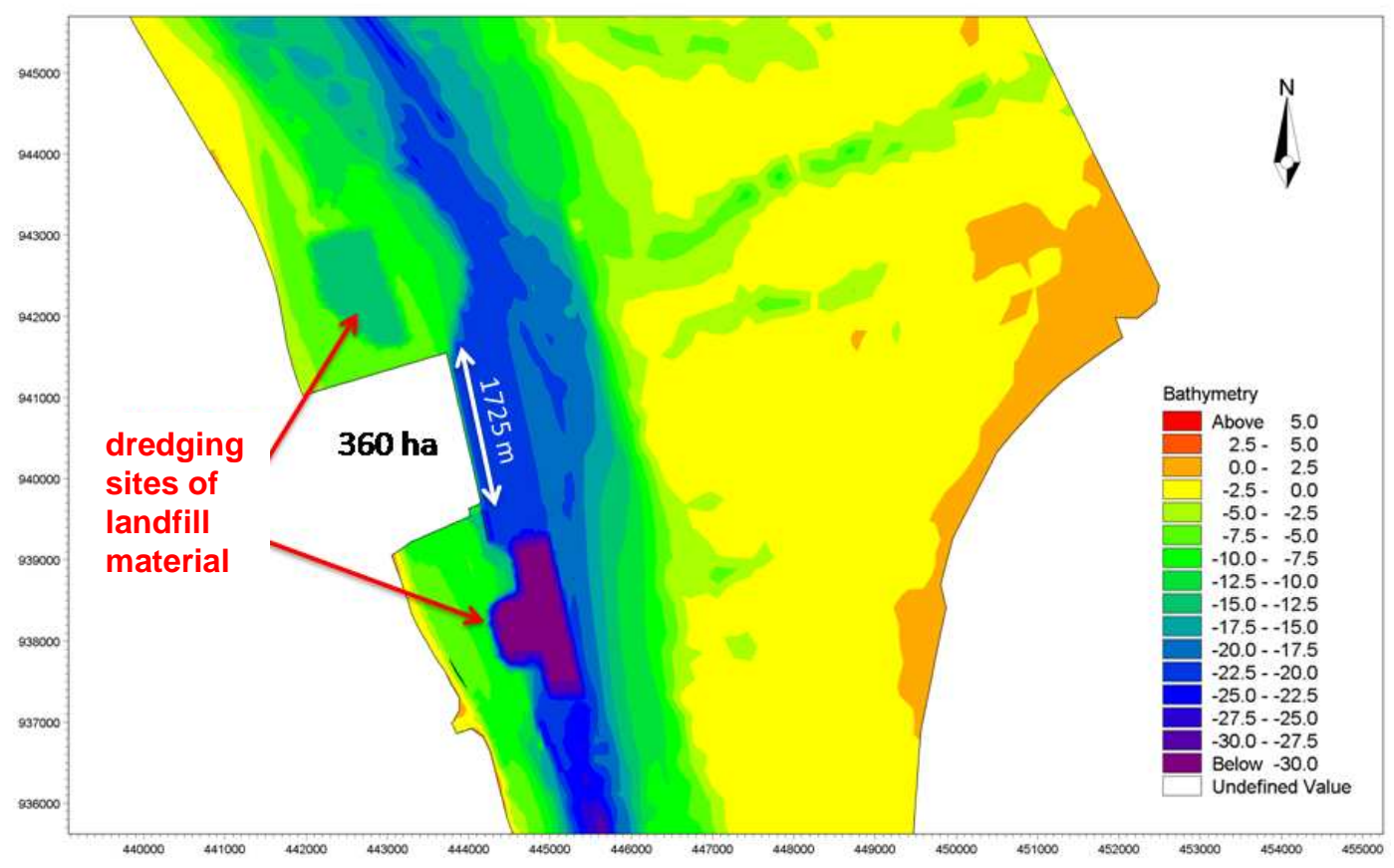

Figure 2. Detail view of the model showing the designed port area, indicating the sites where the landfill material was dredged from. 
MODEL

A 3-dimensional model was set up to simulate the sediment transport inside the Jade estuary to assess the morphological changes as well as the suspended sediment concentration. For this purpose the Software MIKE 3 FM by DHI was applied. Therein the Hydrodynamic (HD) module simulates hydrodynamic processes like current velocities, discharge and water level. The Mud Transport module (MD) applied afterwards solves equations for the sediment transport of fine material at the river bed and in suspension.

MIKE 3 FM uses a Finite Volume approach. The Hydrodynamic module (HD) solves the timedependent conservation equations of mass and momentum in three dimensions, the incompressible Reynolds-averaged Navier-Stokes equations invoking the assumptions of Boussinesq and of hydrostatic pressure. The flow field and pressure variation are computed in response to a variety of forcing functions, when provided with the bathymetry, bed resistance, wind field, hydrographical boundary conditions, etc. The conservation equations for heat and salt are included as well. MIKE 3 uses the UNESCO equation of state of seawater (1980) as the relation between salinity, temperature and density (DHI, 2009 a).

After completing the calibration of the hydrodynamic the Mud Transport module was applied. The module contains the transport of cohesive and non cohesive material. Furthermore, erosion and resuspension of settled material is considered in the module. The Mud Transport module includes processes such as multiple mud fractions, multiple bed layers, wave current interaction, flocculation, hindered settling, inclusion of a sand fraction, transition of sediment between layers and simple morphological calculations. The sediment transport formulations are based on the advection dispersion calculations in the HD module. It solves the advection dispersion equation. In case of multiple sediment fractions the equation is extended to include several fractions while deposition and erosion processes are connected to the number of fractions (DHI, $2009 \mathrm{~b}$ ).

\section{Model Set-Up}

The 3-dimensional approach allows a discretization in horizontal as well as vertical direction, where the vertical direction (water column) takes the free surface into account using a sigma-coordinate transformation approach. Hence, the water column can be divided into several layers. Using the Flexible Mesh (FM) approach the horizontal discretization can consist of triangular and quadrilateral elements. These are cell centered and form an unstructured mesh.

The Flexible Mesh approach allows the discretization of the model area in varying grades of high and low resolution. Areas with a small elevation gradient and of no further interest can be described with large elements, whereas the area of investigation is discretized with small elements.

The model area as shown in Fig. 3 shows a high density of elements in the area of investigation with a maximum element size of $2000 \mathrm{~m}^{2}$ and a minimum element size of $170 \mathrm{~m}^{2}$. The resolution decreases towards the model edges. The Jade bay in the South as well as the Wadden area in the North East of the model have an even bathymetry, hence the element size could be increased up to $120000 \mathrm{~m}^{2}$. For the vertical resolution 10 equidistant layers where defined (see Fig. 4). Using the sigma - coordinate system, the layer thickness depends on the water level and water depth and is varying accordingly. Using the 3-dimensional approach allows the extraction of results for concentration rates of suspended material. 


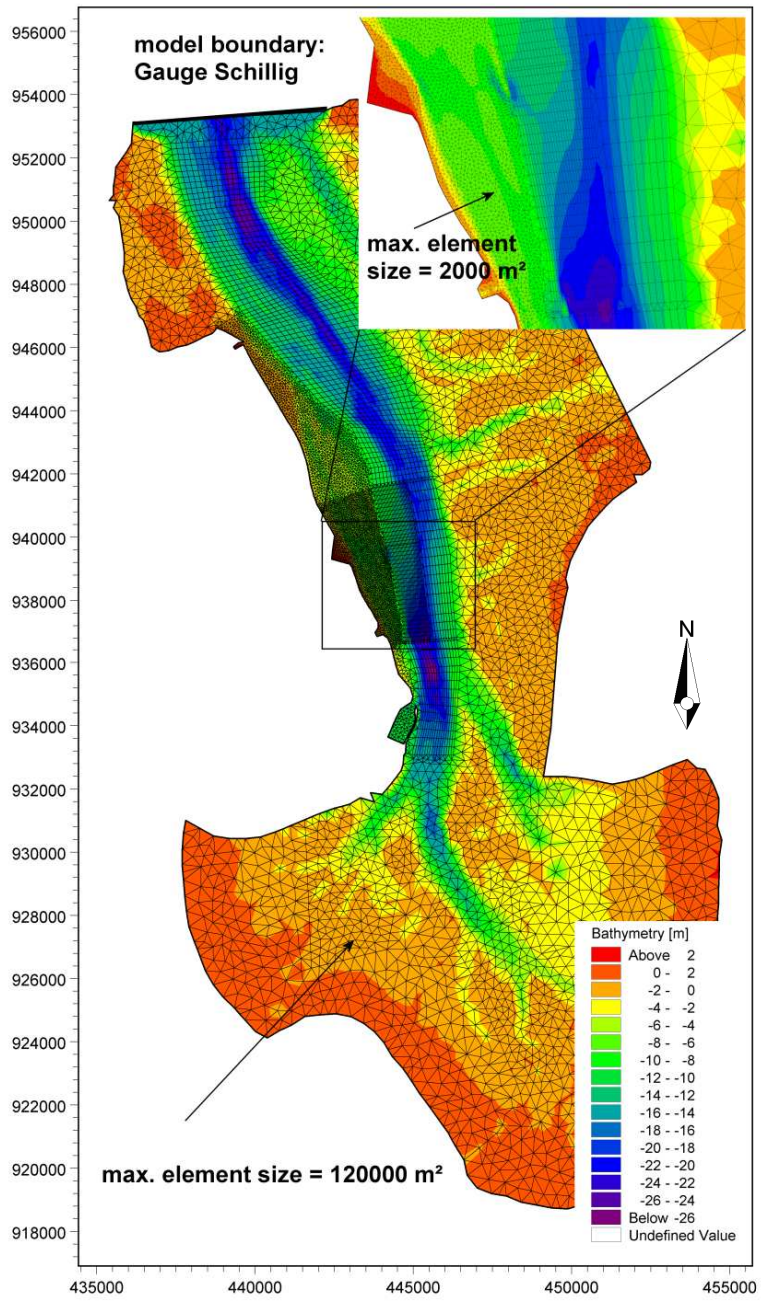

Figure 3. Model area with bathymetry and model discretization.

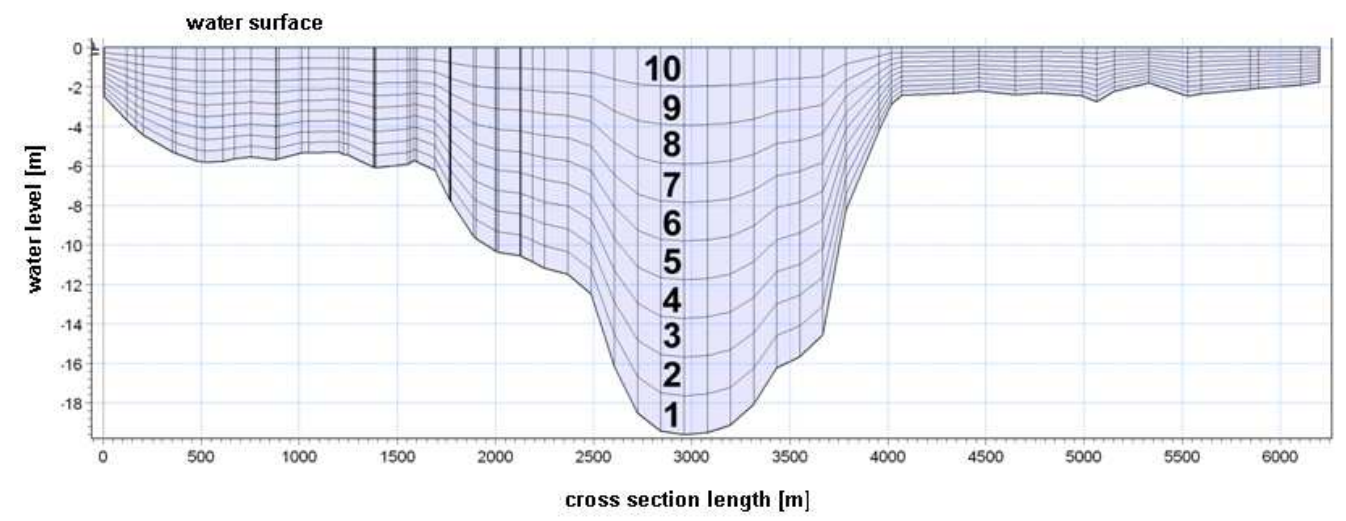

Figure 4. Vertical resolution of the model.

\section{Model Input}

The input data for the numerical model must be divided into hydrodynamic data and morphological data. Whereas the available hydrodynamic data was extensive, the information about the morphology was limited. 
The bathymetry of the model itself was set up by using combined data sets of laser scan data (Wadden area and areas with a low water depth) and echo sounder data (fairway).

For the simulation of the hydrodynamic, data sets on water level, discharge and current velocity measurements were available. At the model boundary the measured water level of gauge Schillig was triggered (compare Fig. 3). Inside the model area the water level measured at gauge Voslapp was used for comparison. Two ADCP measurements provided data to compare the discharge within the model at two different cross sections. Additionally, the current velocities measured at four different sensor locations were compared with the modeled current velocities.

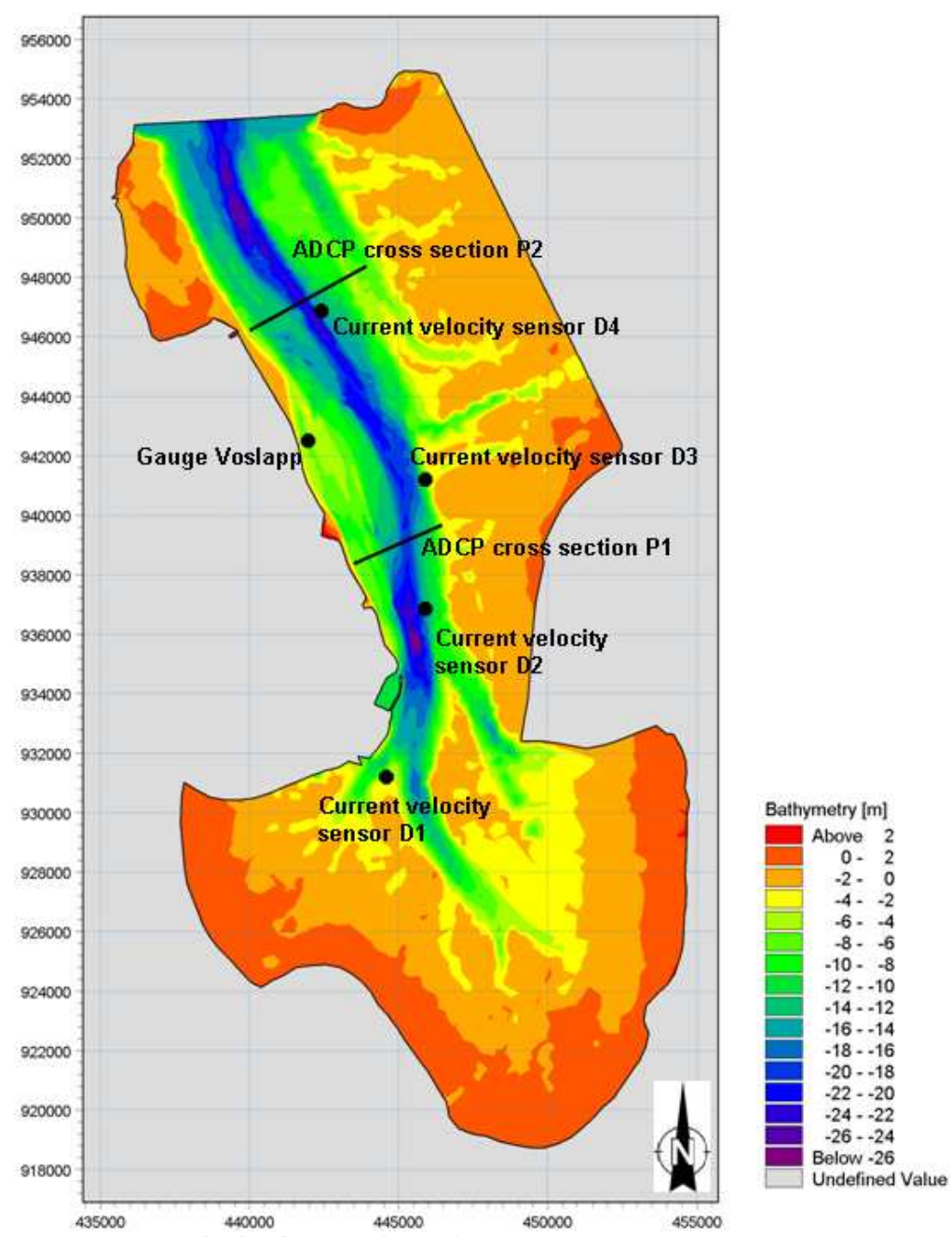

Figure 5. Model area indicating locations of parameter measurements.

In the beginning of the study the available information on the morphology was quite limited. A study about the affect of the JadeWeserPort on the morphodynamic changes in the Jade estuary provided an overview on the sediment, soil condition and suspended sediment concentration (BAW, 2003). Earlier more extended studies on the sediment of the Jade barely exist.

Assumptions had to be made as well as factors such as the influence of the waves had to be neglected. As measured data on the wave conditions were not available it was decided to neglect the influence as the effect of wave induced erosion (on the Wadden area) has merely no impact on the area of interest. Here the currents are the dominant factor for erosion. However, when analyzing the results these assumptions were put back into account. As input parameters two fractions were defined, fine sand and silt. These two materials are the predominant sediments in the Jade estuary (BAW, 2003). The distribution of the material was defined as an erodable layer of the bed and it was brought into the model at the northern boundary (Schillig). 
Model Calibration

Comparing the measured and modeled hydrodynamic parameters water level, discharge and current velocity the results showed a very good correspondence (Fig. 6).

(a)

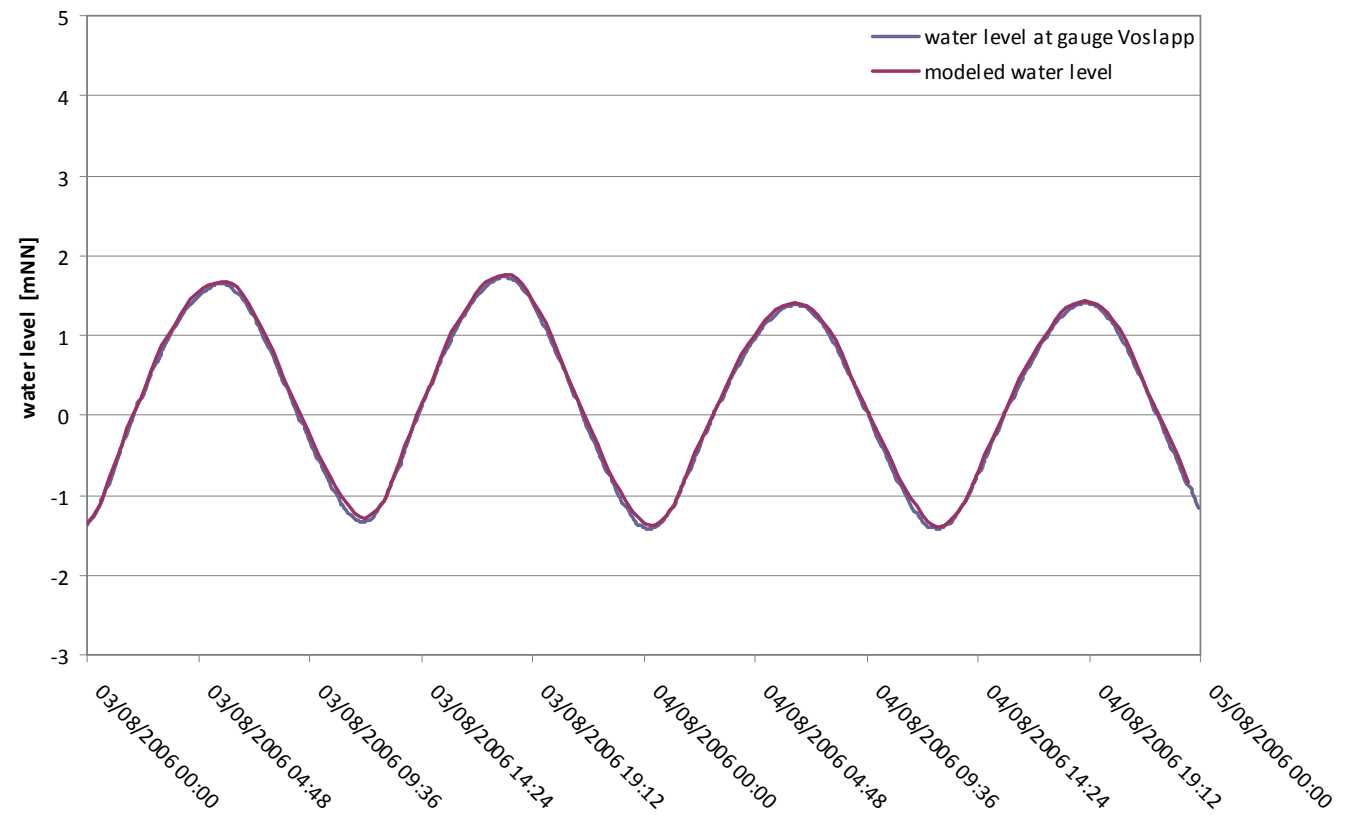

(b)

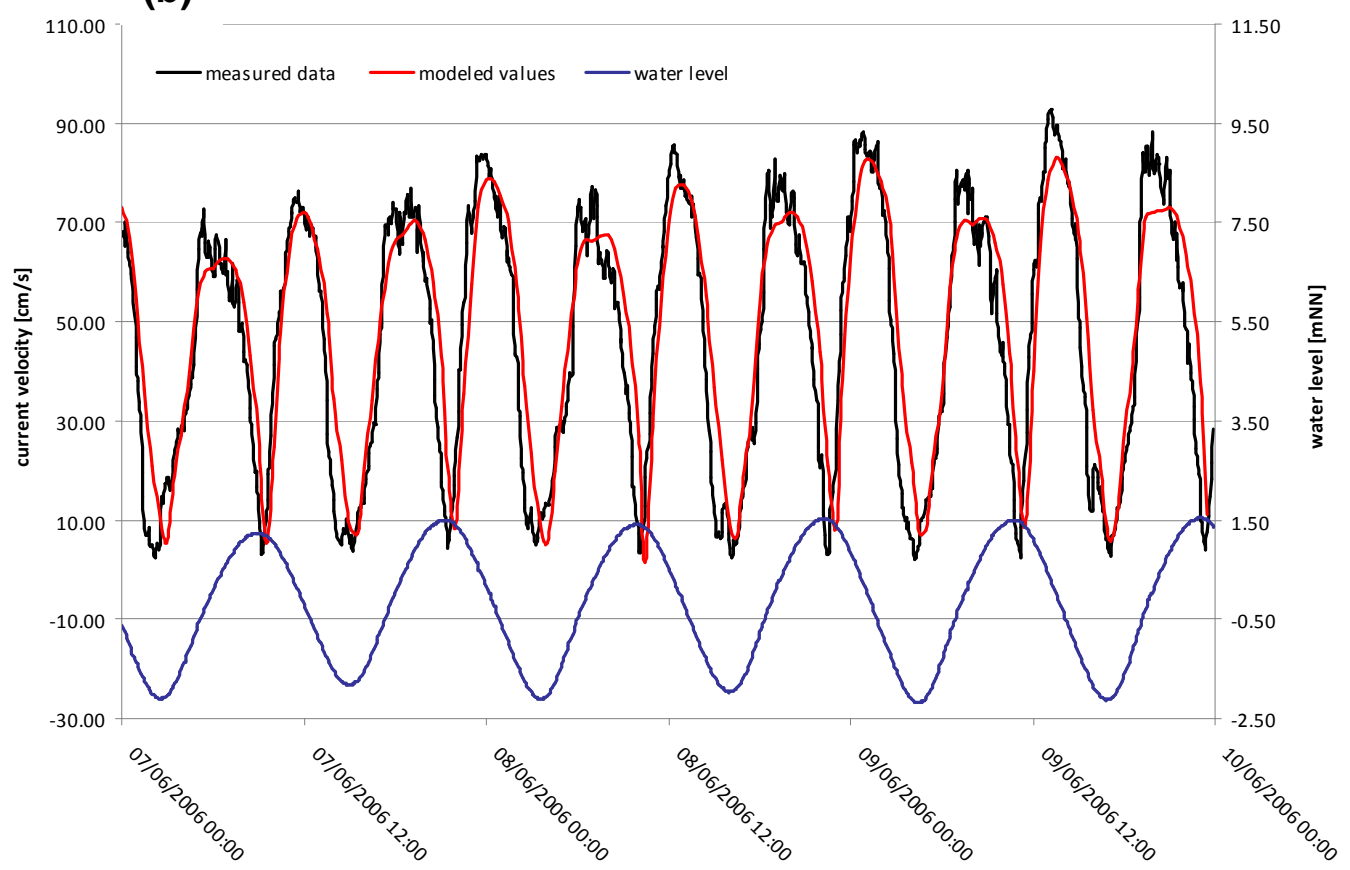


(c)

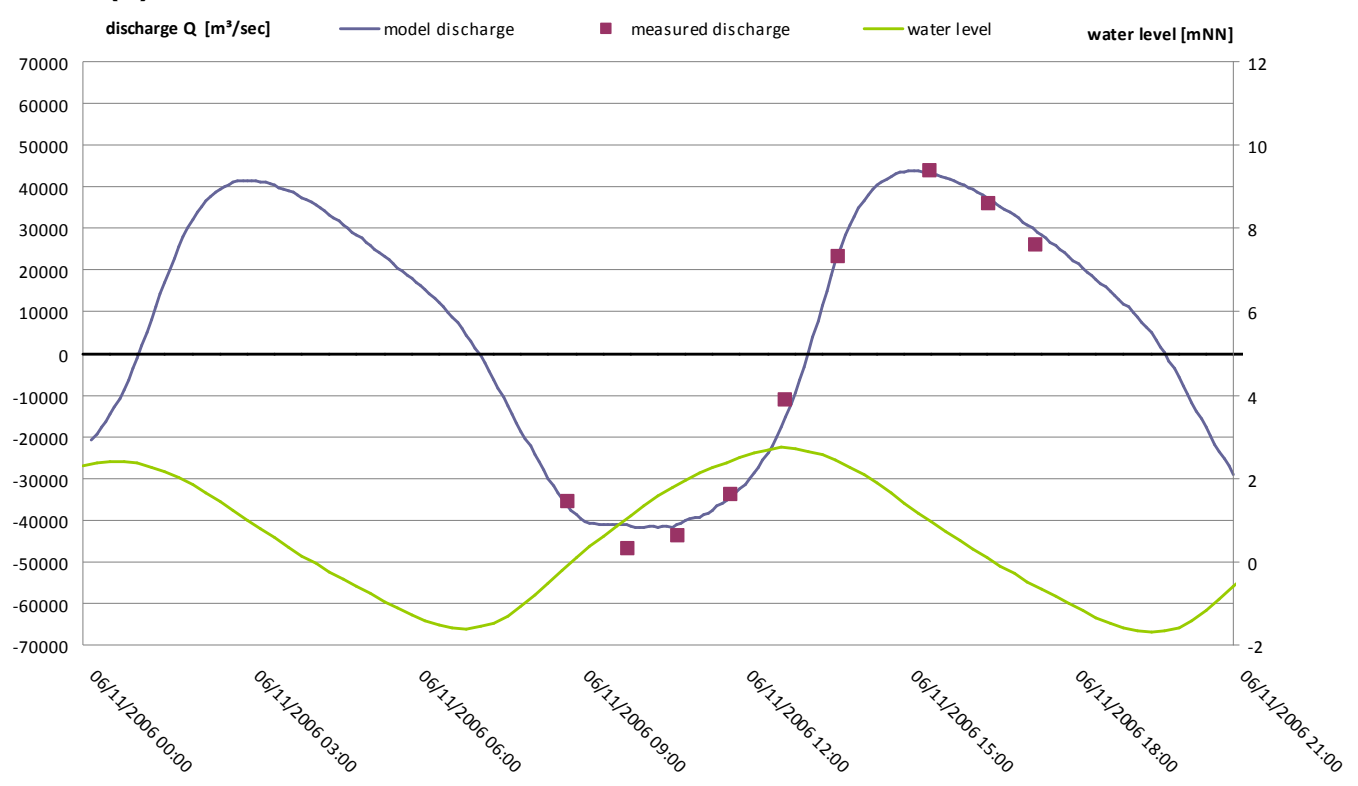

Figure 6. Measured and modeled hydrodynamic parameters water level (a), current velocity (b) and discharge (c).

Calibrating the morphology was more difficult due to the missing data sets. Based on one set of surveyed bathymetry data the morphodynamic changes before and after beginning of the port construction were modeled. The available data set showed the area south of the port before any port construction - landfilling - had started. This set was applied as bathymetry for the initial situation. The $2^{\text {nd }}$ survey took place after the sheet piling of the southern side of the port was finished. Between the two sets laid about one year. These two sets were used to set up the morphodynamic model. It was then adjusted in terms of available sediment for erosion and deposition. The model results were verified by using another two data sets surveyed in January and July 2009. Again the sheet piling was finished, furthermore, the landfilling had started. The material for that was taken from the nearby southern dredging site (compare Fig. 2). Hence, the morphological balance in the area was disturbed and the relocation of sediment had started, as indicated in Fig. 7
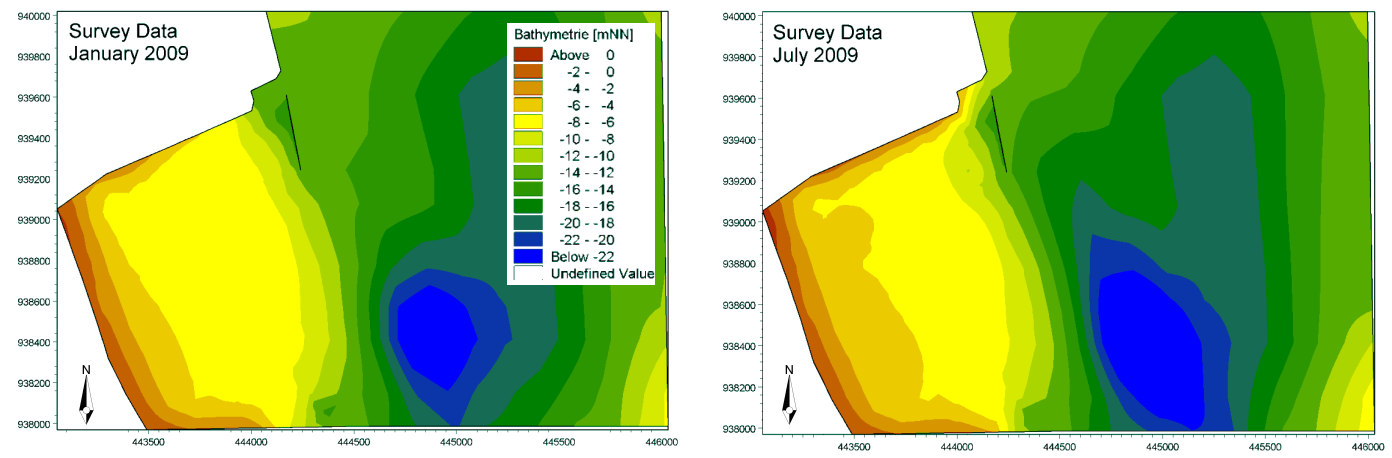

Figure 7. Survey data January and July 2009, showing the bathymetry south of the port.

The difference of the surveyed data sets was then estimated (Fig. 8) and compared with the model results (Fig. 9). The modeled time frame was 4 weeks, the sedimentation rate after this time was then extrapolated to 6 months. The dashed line in both figures marks the extent of the surveyed area. Hence, the area that could be compared was limited. Furthermore, the blue to violet areas in Fig. 8 mark the areas where the dredging for the landfill material took place. These decreased the possible area for comparison further. Locations that could be compared are indicated by the red numbered rectangles. In here the model describes the sedimentation tendencies of the observed movement accordingly. 


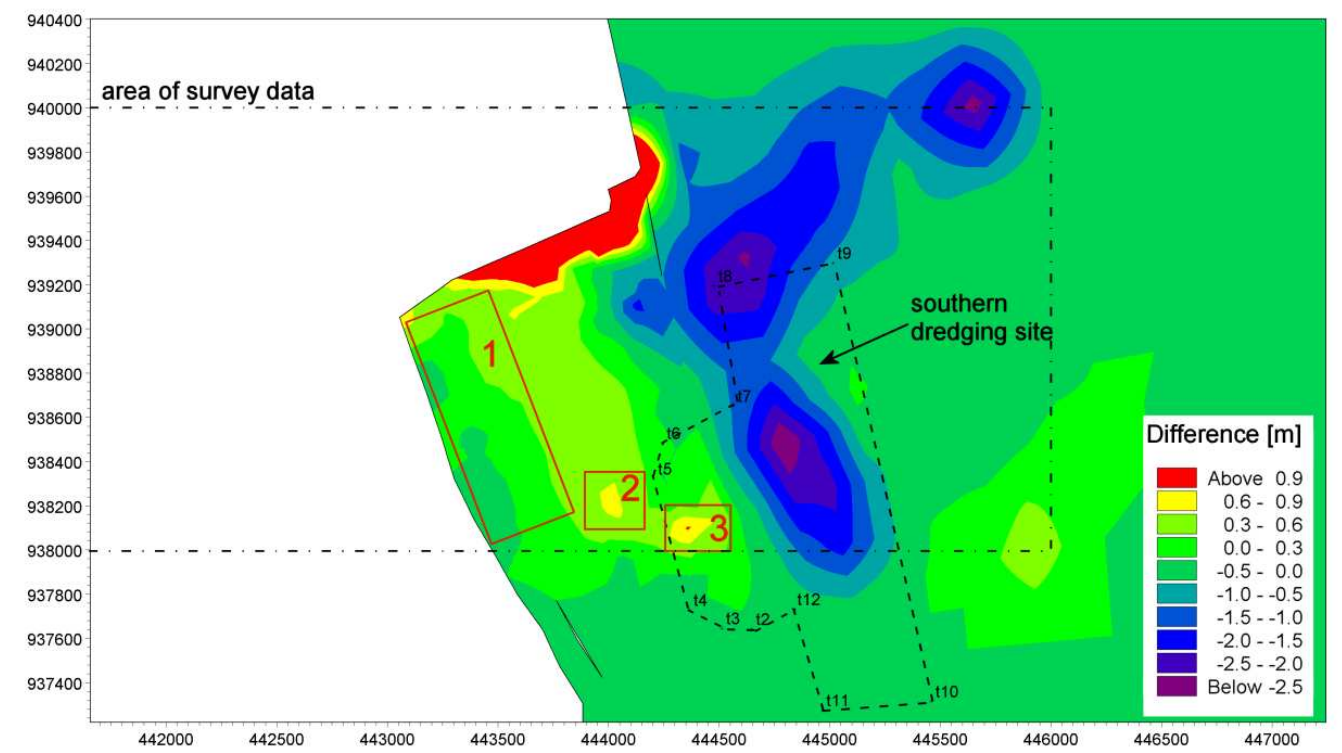

Figure 8. Difference of surveyed data between January and July 2009.

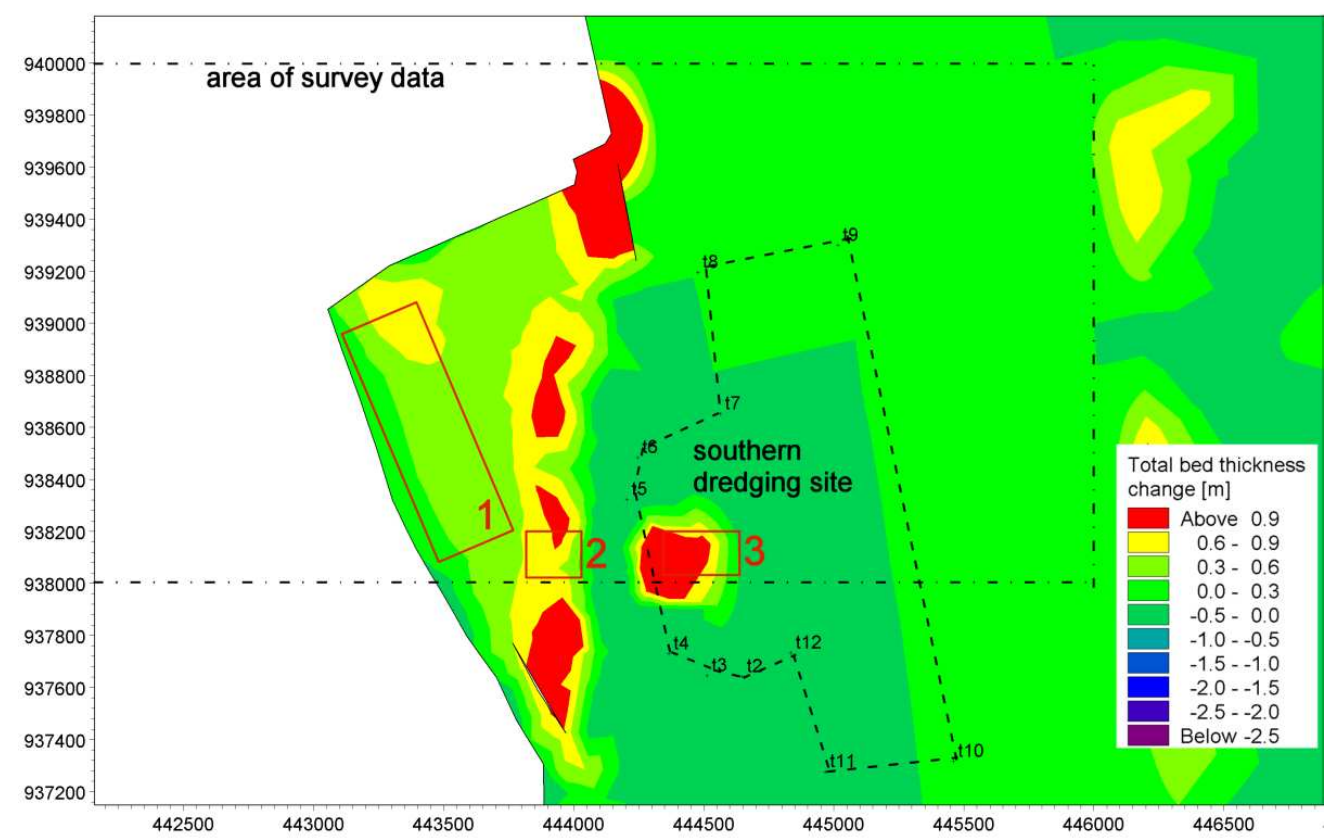

Figure 9. Modeled sediment transport extrapolated for 6 months.

\section{ANALYSIS}

Modeling sediment transport as a consulting company is supposed to solve actual problems regarding construction processes, design decisions and project planning. DHI-WASY was contracted by various companies to analyze the movement of the sediment after being forced to relocate due to the dredging and the port construction. The questions to be answered included the prediction of a morphological final state. This state is reached when the sediment is moving within a range that can be regarded as stable, where erosion and sedimentation rates form a balance. Additionally, the expected elevation of the river bed was of interest for the designers of two nearby power plants to ensure the stability of constructions standing in the water body. Furthermore, actual problems during the construction period were answered such as modeling the current velocities and sedimentation rate within an installation channel for pipes. Finally, it was investigated to what extent dredged and 
discarded clay could be used being dumped under water to form a barrier to enforce sedimentation in a certain area.

\section{RESULTS}

Representative for the performed investigations, in the following the determination of the morphological final state is stated. The morphological final state was determined iteratively by running various models with changing bathymetries. The different expected river bed elevations were derived by the hydrodynamic results and the evaluation of the survey data.

Sediment transport is highly depending on the current velocities and current conditions. A major change in the current velocities is causing erosion or sedimentation. Additional impacts on the river bed such as dredging activities force the morphology to adapt to the new situation or more likely to reestablish a morphological stable state.

Fig. 10 shows the current velocities during maximum flood and ebb flow in the area of investigation. The ebb flow is running parallel to the coast before being forced eastwards to flow around the port. Before the port was constructed the current would have flown along the shoreline during flood and ebb flow. The port now causes the flood flow to turn into a circular movement south of the area. In the centre of this circular flow the current velocities decrease. It was assumed that this would lead to an increase of sedimentation at the same location.

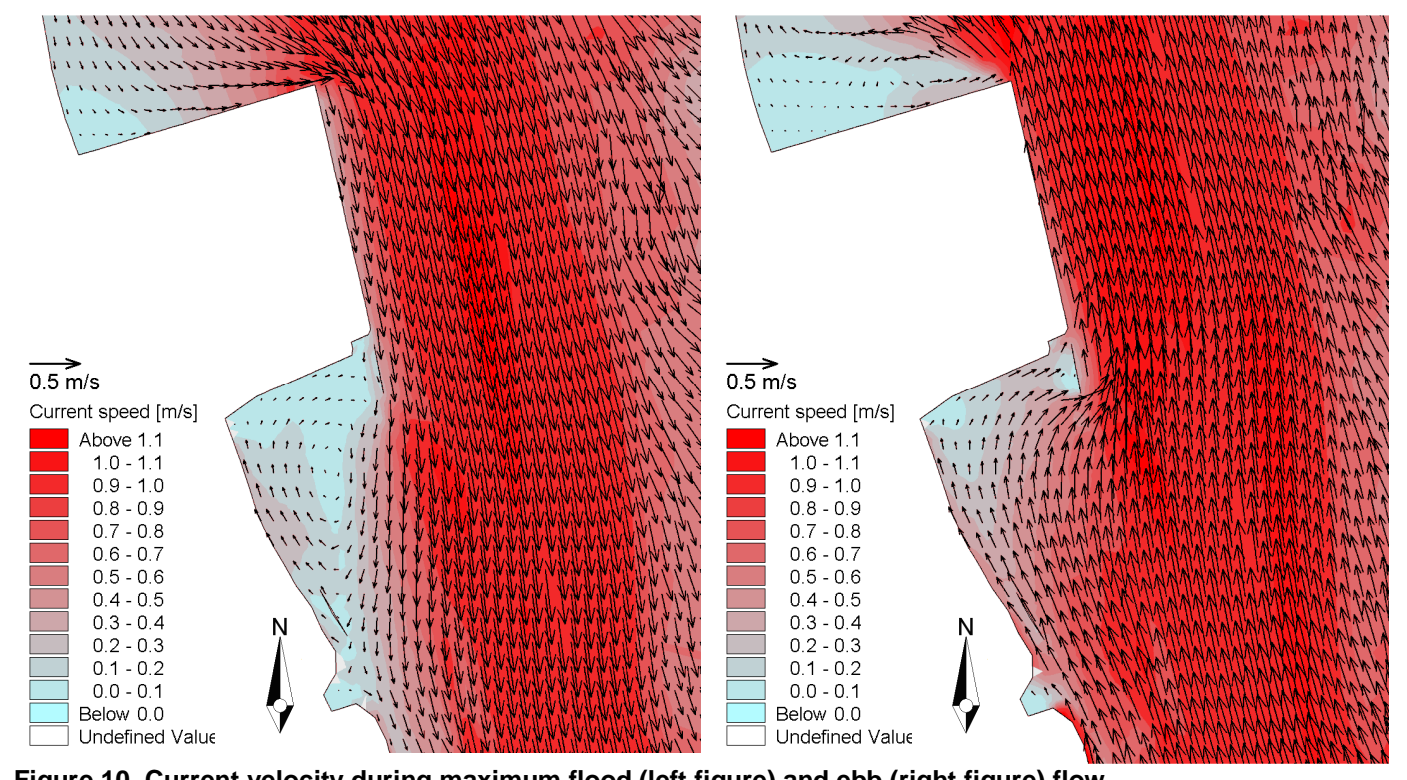

Figure 10. Current velocity during maximum flood (left figure) and ebb (right figure) flow.

Looking into the different sets of survey data of the bathymetry (Fig. 11), the change of the river bed elevation within 2 years was analyzed. The results as well as the afore mentioned changes in the current velocities and directions were used to determine a morphological final state. Therefore, the data of the latest survey was taken as model bathymetry, it was then adjusted manually according to the analysis of the evaluated bathymetry sets. After each following run the bathymetry was modified until the results showed almost no sedimentation or erosion activity in the area. It was then concluded that the morphology reached a stable state. The iteratively determined bathymetry is shown in Fig. 12. For this bathymetry the model results (right figure) show no further sedimentation especially in the approximate centre of the circular flow during flood flow.

The result of the expected developing river bed elevation was of special interest for the clients with constructions in the water body. For example, based on the study the foundations of the constructions were designed. 

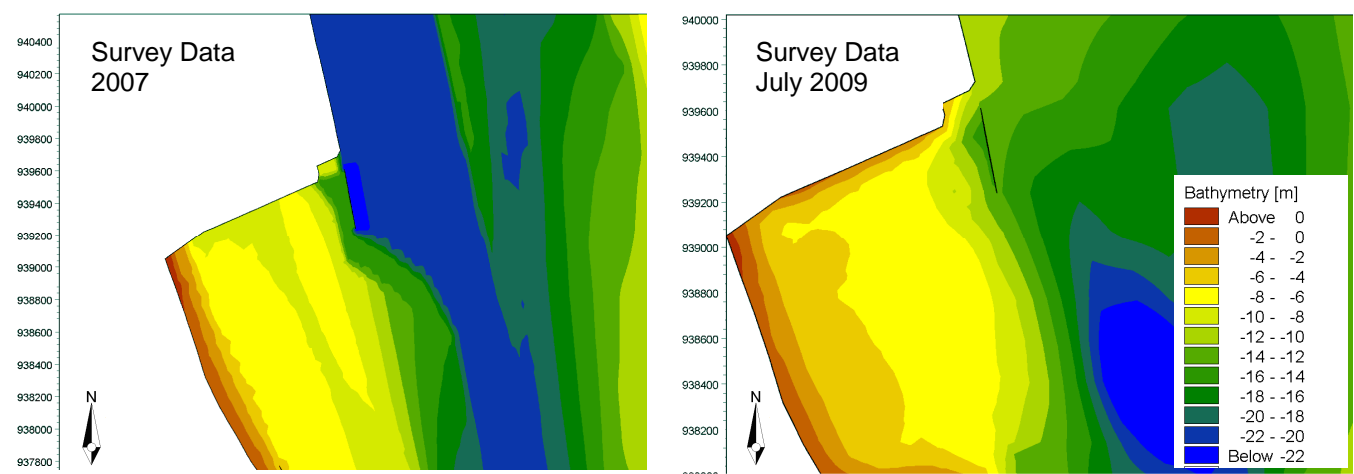

Figure 11. Survey data 2007 and 2009 showing the changes of the river bed south of the port.
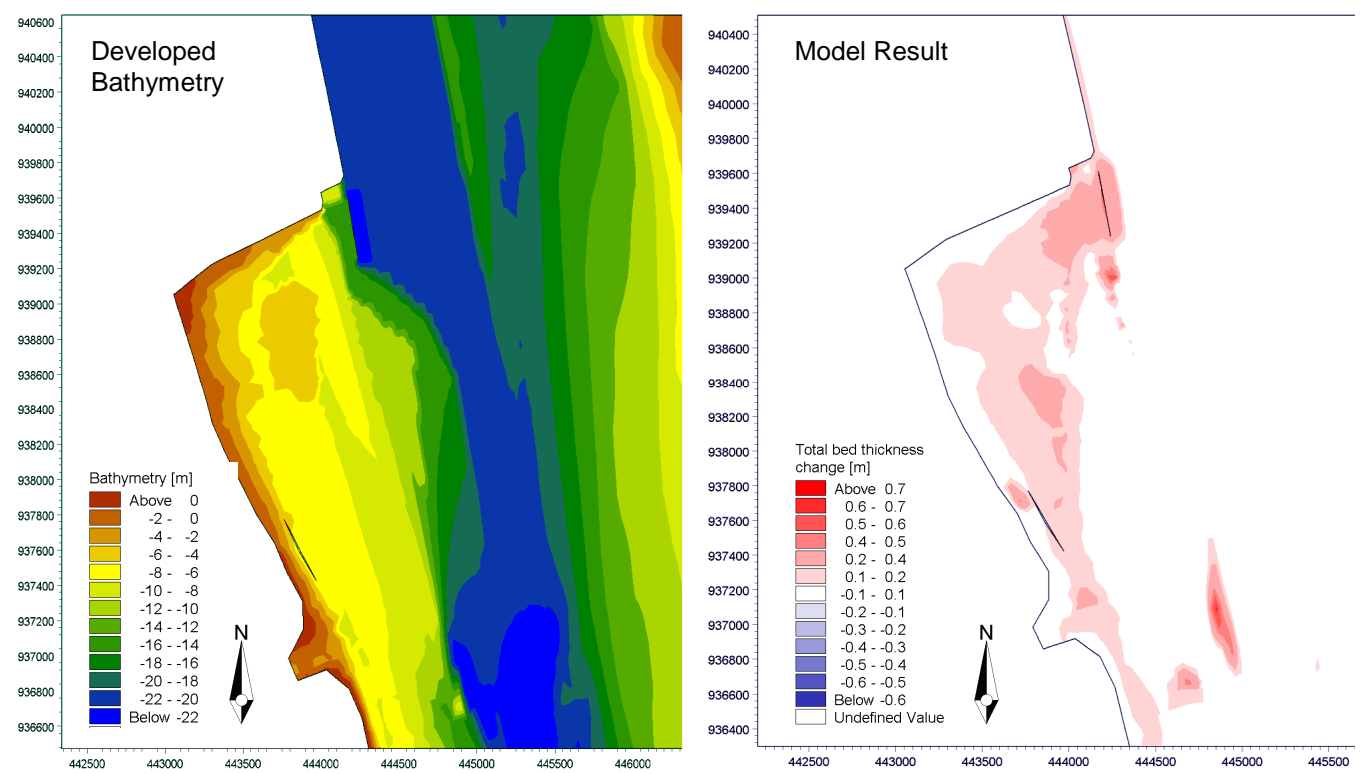

Figure 12. Iteratively developed bathymetry and model results (total bed thickness change).

\section{CONCLUSION}

The investigation at hand showed that even as a consulting institution modeling sediment transport is an important tool for the decision makers and designers when it comes to interferences on coastal water bodies and the resulting effects on the morphodynamic. Each major construction within an estuary or river is causing changes in the current conditions, which itself is affecting the morphodynamic of the nearby area. These morphodynamic changes must be considered in the design process of constructions interacting or being placed in the water body. Therefore, as shown in the study, modeling the sediment transport is a useful tool. Although the input data on the morphology was very limited and extensive surveying and monitoring campaigns could not take place prior to the modeling, it was shown that results could be gained and were verified by additional data. However, it must be stated that the morphological study was based on a very reliable hydrodynamic model, that itself had various measured data sets for calibration and verification. Hence, the results of the morphological study were reviewed for plausibility using the hydrodynamic results. The investigations at hand showed that more and more modeling sediment transport is not a mere research tool but can also be used for consulting and design purposes.

\section{REFERENCES}

BAW. 2003. Untersuchungen zum Einfluss des Jade Weser Ports auf die Morphodynamik der Jade. $B A W .5 .02 .10020 .00$.

DHI. 2009. MIKE 21 \& MIKE 3 Flow Model FM Hydrodynamic and Transport Module - Scientific Documentation. MIKE by DHI, Horsholm, Denmark. 
DHI. 2009. MIKE $21 \&$ MIKE 3 Flow Model FM Mud Transport Module - Scientific Documentation. MIKE by DHI, Horsholm, Denmark.

Landesamt für Natur und Umwelt Schleswig Holstein. 2000. Deutsches Gewässerkundlichs Jahrbuch Küstengebiet der Nordsee. LANU, Flintbek, ISSN: 1437-0808. 